\title{
Pediatric Bipolar Disorder: Diagnosis and Management
}

\author{
Areeg Osama El Shaarawy* \\ Ain Shams University Hospital, Egypt \\ *Corresponding author: Areeg Osama El Shaarawy, Ain Shams University Hospital, Egypt
}

\section{Introduction}

Bipolar disorder in children and adolescents is characterized by recurrent episodes of elevated mood (mania or hypomania) that exceed what is expected for the child's developmental stage and are not better accounted by other psychiatric and medical conditions. In addition, youth with bipolar disorder usually have recurrent episodes of major depression [1-3]. Identification of the illness and initiation of treatment occurs, on average, 10 years after its manifestation [4]. that is a grave problem that could be avoided if pediatricians become more aware of the warning signs of mental illness in children, to help us treat the problem early on. It's absolutely necessary to obtain a good history from parents and caregivers, to help diagnose the child and help decide on the appropriate line of management. The child will also need proper education about his condition in a way that is easy to understand for their age. The following symptoms are suspicious of pediatric bipolar disorder:

a) Decreased need for sleep for a long period of time.

b) Increased activity, beyond what is expected for the developmental age of the child.

c) Inappropriate sexual behaviors, that occur without a history of exposure to sexual activity (eg. Abuse or videos).

d) Psychosis (eg, hallucinations and/or delusions) may be present.

\section{Assessment}

We use structured and semi-structured interviews and rating scales; as well as careful examination and observation of the child in more than one setting, after obtaining a detailed history.

\section{Diagnosis}

We use the criteria in the American Psychiatric Association's Diagnostic and Statistical Manual of Mental Disorders, Fifth Edition (DSM-5) [5].

\section{Mania}

a) Grandiosity b) Decreased need for sleep

c) More talkative than usual

d) Flights of ideas

e) Distractibility

f) Increase in goal-directed activity or psychomotor agitation

g) Excessive involvement in pleasurable activities (eg, shopping or sexual indiscretions)

\section{Depression}

a) Depressed mood most of the day, nearly every day (dysphoria).

b) Diminished pleasure in nearly all daily activities (anhedonia).

c) Insomnia or hypersomnia nearly every day.

d) Psychomotor agitation or retardation.

e) Fatigue nearly every day.

f) Inappropriate guilt nearly every day.

g) Diminished ability to think nearly every day.

h) Recurrent thoughts of death or suicidal ideations, or suicidal attempts.

Episodes of mania, hypomania and major depression can be accompanied by symptoms of the opposite polarity and are referred to as mood episodes with mixed features.

\section{Differential Diagnosis}

The main psychiatric conditions that can be difficult to differentiate from bipolar disorder in youth are:

a) Attention deficit hyperactivity disorder (ADHD).

b) Autism spectrum disorder. 
c) Conduct disorder.

d) Disruptive mood dysregulation (DMDD).

e) Oppositional defiant disorder.

f) Schizophrenia.

g) Substance use disorder.

h) Unipolar depression.

The diagnosis of bipolar disorder in youth can be complex as bipolar disorder id often accompanied by comorbid disorder. The management of bipolar disorder involves:
a) Pharmacotherapy.
b) Psychotherapy.
c) Brain Synchronization Therapy (if indicated).

\section{References}

1. Birmaher B, Axelson D, Pavaluri M (2007) Bipolar Disorder. In: Lewis' Child and Adolescent Psychiatry: A comprehensive textbook, $\left(4^{\text {th }}\right.$ edn), Martin MA, Volkmar FR, Lewis M (Eds), Lippincott Williams \& Wilkins, London.

2. Pavuluri MN, Birmaher B, Naylor MW (2005) Pediatric bipolar disorder: a review of the past 10 years. J Am Acad Child Adolesc Psychiatry 44: 846.

3. Birmaher B, Axelson D, Goldstein B (2009) Four-year longitudinal course of children and adolescents with bipolar spectrum disorders: The Course and Outcome of Bipolar Youth (COBY) study. Am J Psychiatry 166: 795-804.

4. Goodwin FK, Jamison KR, Ghaemi SN (2007) Manic-Depressive Illness: Bipolar disorders and recurrent depression, $\left(2^{\text {nd }}\right.$ edn $)$, Oxford University Press, New York.

5. (2013) Diagnostic and Statistical Manual of Mental Disorders, Fifth Edition (DSM-5), American Psychiatric Association, Arlington.

\section{(c) $\left(P_{\mathrm{BY}}\right.$ \\ This work is licensed under Creative Commons Attribution 4.0 License}

To Submit Your Article Click Here: Submit Article

DOI: $10.32474 /$ RRHOAJ.2019.03.000173

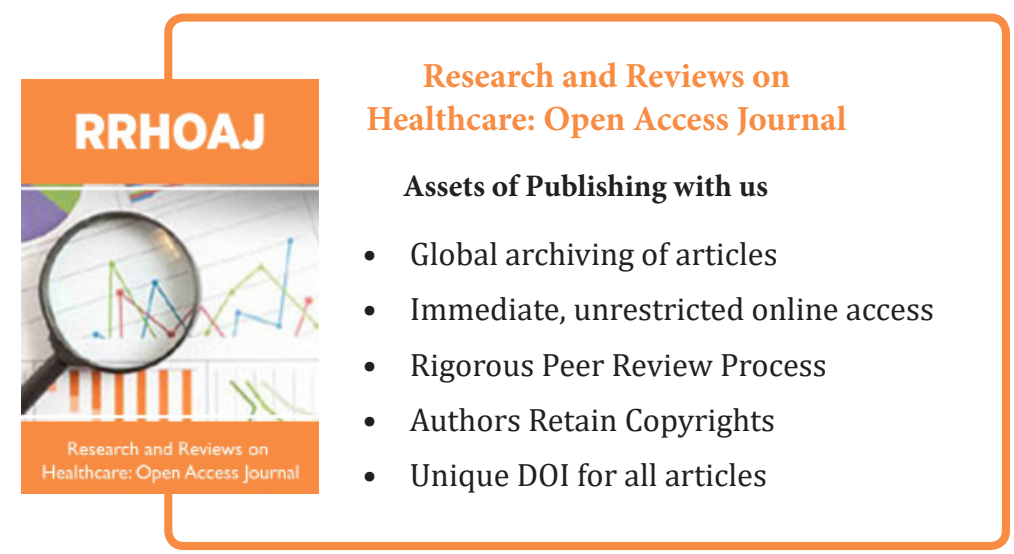

